\title{
Countercurrent Reduction of Powder Ore in a Drum-type
}

\author{
Rotary Fluidized Bed ${ }^{*}$
}

\author{
By Masayoshi AMATATSU,** Yasushi TAKAMOTO*** and \\ Tanekazu $S \bar{O} M A^{* *}$
}

\section{Synopsis}

In order to increase the gas utilization and to prevent the sintering phenomena in fluidized bed, experiments of countercurrent reduction of powder ore with $\mathrm{CO}$ gas were carried out in a drum-type rotary fluidized bed at the temperature of 750 and $900^{\circ} \mathrm{C}$. In a modeling vessel (diameter: $30 \mathrm{~cm}$ ), the rotary fluidized state could be obtained on the conditions that the filling ratio of powder ore was from 30 to $50 \%$ and the dimensionless rotary speed $(F)$ was from 1.0 to 1.2 at room temperature.

The motion of powder ore in the drum-type rotary fluidized bed was seemed to be a completely back-mixing flow. The gas-utilization coeffcient was maximum on $F=1.0$, and it could be increased up to the stoichiometric equilibrium concentration for the reduction of ore.

The results of a mathematical calculation by using the dimensionless numbers (Gc and $O t$ ) for the countercurrent reduction based on the threeinterface unreacted core model were in good agreement with observed data.

\section{Introduction}

It is well known that the blast-furnace and LDconverter processes are representative of the present iron and steelmaking technology. In connection with many problems, such as a massive expenditure for the installations of steel works and a change in worse supply-demand relation of energy source, a new ironmaking process in the district where the reducing agents, for example natural gas, are cheap has been started to develop. Many reports on the present status of direct reduction technology, such as general reviews ${ }^{1,2)}$ and particular discussions ${ }^{3,4)}$ were published.

According to these reports, the direct reduction process can be an alternative for the blast furnace by improving the existing technology and by spreading the energy source. A review of ironmaking process by fluidizing bed has been published, ${ }^{5}$ ) and also the present study is a subject of this fluidizing bed process.

The advantage of the fluidizing bed process is characterized by a great specific surface area of fine ore, namely a great reaction rate, and an easy continuous operation. On the other hand, a vertical fluidized bed is restricted by insufficient gas utilization due to by-passing as bubbles and agglomerating or sintering phenomena of reduced iron. Therefore, it is an important problem to improve the gas utilization and to prevent the sintering phenomena.

For the improvement of gas utilization, the flow of gas and solid were tried to be a countercurrent flow by arranging the multi-stage reactors, ${ }^{6-8}{ }^{9-}$ the dispersing plate in the lower part of reactor, ${ }^{9-12}$ and horizontal internals in a two-dimensional reactor. ${ }^{13)}$
On the other hand, certain ore fines have an inevitable tendency to stick together and form agglomerate during reduction reaction. Sticking or sintering of ore fines during reduction can be minimized by the use of extraneous materials, ${ }^{14-16)}$ and by arranging the stirrer ${ }^{17)}$ and a rotating disk in a vertical fluidized bed. ${ }^{18)}$

The experiments on the countercurrent reduction of powder ore in a rotary fluidized bed were previously reported..$^{19-22)}$ The reactor with a slight gradient was rotated at high rotary speed to balance the centrifugal force and gravity. On the rotary fluidized state, the contact of ore fines and reducing gas will be better than that in the conventional rotary-kiln furnace. This reactor can be also operated as a countercurrent flow characterized by a shaft furnace, and hence the reaction efficiency of this reactor may be attained to that of the shaft furnace. By the previous experiments, ${ }^{19-22)}$ a straight tube-reactor which was divided into a few rooms was used. The residence weight of ore in the reactor depended sharply on a shape of sectors, and thus it was not always stable.

In order to maintain the stable residence weight of powder ore in the reaction zone, the reaction tube was made up of a drum part as the reaction zone that had larger diameter, and two branch-tubes for charge and discharge of powder ore and reducing gas. This reactor was rotated with a slight gradient of 1 and 3 deg against horizontal. This reactor is named as the drum-type rotary fluidized bed. Observation of particle motion, measurement of particle mixing and countercurrent reduction of powder ore with $\mathrm{CO}$ gas as well as a mathematical calculation were carried out by using this reactor.

\section{Experimental Apparatus and Procedure}

\section{Iron Ore and Reducing Gas}

A hematite iron ore (Mt. Newman) was used for powder ore and was sieved from 0.71 to $1.0 \mathrm{~mm}$ and from 0.42 to $0.71 \mathrm{~mm}$. The chemical composition of iron ore is shown in Table 1. CO gas which was produced by the reaction of $\mathrm{CO}_{2}$ and activated carbon at the temperature of $1100^{\circ} \mathrm{C}$ was used for reducing gas. It contained impurities at maximum $2 \%$, such as $\mathrm{N}_{2}$ and $\mathrm{H}_{2}$. Gas flow rate was measured by gas meter and was 1 to $6 \mathrm{~N} l / \mathrm{min}$. The waste gas was analyzed by infrared gas analyzer for $\mathrm{CO}$ and $\mathrm{CO}_{2}$.

\footnotetext{
* Originally published in Tetsu-to-Hagané, 66 (1980), No. 13, Special Issue on Ironmaking, 1995, in Japanese. English version received August 12, 1982. (C) 1983 ISIJ

** Faculty of Engineering, The University of Tokyo, Hongo, Bunkyo-ku, Tokyo 113.

*** Formerly Graduate School, The University of Tokyo. Now at Hirohata Works, Nippon Steel Corporation, Fuji-cho, Hirohata-ku, Himeji 590.
} 
Table 1. Chemical composition of iron ore. (wt\%)

\begin{tabular}{ccccccccccc}
\hline T.Fe & $\mathrm{FeO}$ & $\mathrm{SiO}_{2}$ & $\mathrm{MgO}$ & $\mathrm{CaO}$ & $\mathrm{Al}_{2} \mathrm{O}_{3}$ & $\mathrm{~S}$ & $\mathrm{C} . W$. & Moist. & O* \\
\hline 62.3 & 0.07 & 5.54 & 0.05 & 0.03 & 2.90 & 0.001 & 2.0 & 3.9 & 26.8 \\
\hline
\end{tabular}

$\mathrm{O}^{*}$ : Combined oxygen with iron; Mt. Newman $(D p ; 0.71 \sim 1.00 \mathrm{~mm})$

\section{Reactor of Drum-type Rotary Fluidized Bed}

Figure 1 shows a schematic drawing of experimental apparatus for the countercurrent reduction of powder ore in a drum-type rotary fluidized bed. This reaction apparatus consists of the charging system of powder ore, the reaction zone (drum part) and the discharging system of powder iron. The reaction zone is $65 \mathrm{~mm}$ in diameter and $50 \mathrm{~mm}$ in length. Diameter of axis tube is $25 \mathrm{~mm}$. The edge of axis tube was supported by a bearing roll and sealed by O-ring. The reactor was inclined at horizontal angle of 1 and $3 \mathrm{deg}$ for smooth descent of powder ore.

The powder ore was weighed by a measuring reservoir and then the ore was charged into the reaction zone at intervals of 2 to $4 \mathrm{~min}$. The waste-gas composition changes with intermittent charge of powder ore, but the weight and the intervals of charge could be selected easily so as to keep a change in $\mathrm{CO}_{2}$ content within $1 \%$. After the powder ore of more than double residence weight was charged into the reaction zone, the waste-gas composition attained to a steady value under a constant ratio of ore charging rate to gas flow rate.

The reactor was externally heated up by $\mathrm{Ni}-\mathrm{Cr}$ resistance heater $(1.5 \mathrm{~kW})$. The rotating speed of reactor was measured by a stroboscope. Powder ore was reduced in the reaction zone, and descended from branch-tube to cylinder. The discharge rate of reduced iron was obtained by measuring the descended volume in cylinder.

\section{Experimental Results and Discussion}

\section{Motion of Particles in Drum-type Rotary Fluidized Bed}

\section{Observation of Particle Motion}

A motion of particles in a modeling vessel (diameter: $30 \mathrm{~cm}$, width: $5 \mathrm{~cm}$ ) of the drum-type rotary fluidized bed by taking a photograph was observed as parameters of rotary speed and filling ratio in reactor. With increasing the rotary speed as to balance the centrifugal force and the force of gravity in the reactor, a particle starts up to a parabolic motion from a position $P(r, \theta)$ as shown in Fig. 2. At this position, the following equation is given in disregard of interaction of each particle and of slip on internal surface in the reactor;

$$
m r \omega^{2}=m g \sin \theta
$$

At the apex of the reactor, a rotary speed termed the critical rotary speed $F$ is given by substituting $r=D_{t} / 2$ and $\theta=90 \mathrm{deg}$ into Eq. (1).

$$
\begin{aligned}
& \omega=\sqrt{2 g / D_{t}}=2 \pi f \\
& F=60 f=422.8 / \sqrt{ } D_{t}
\end{aligned}
$$

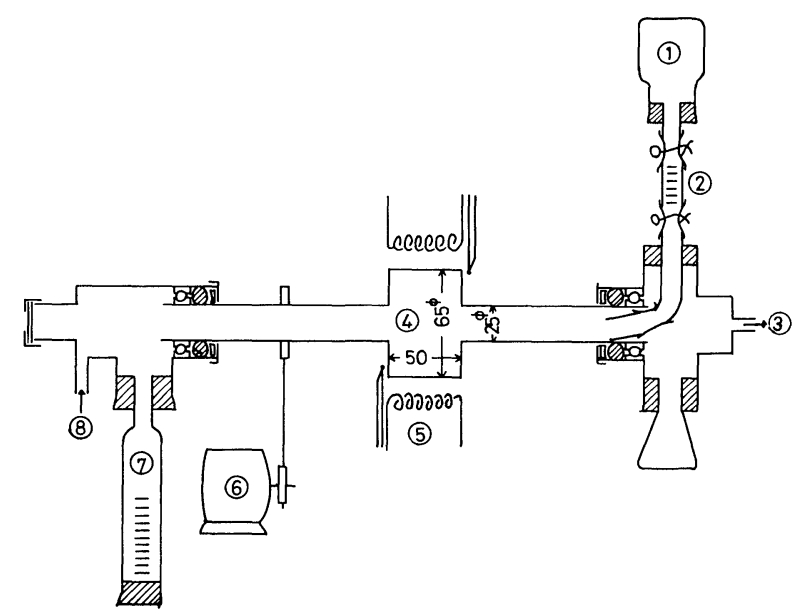
(1) Hopper
(2) Measuring reservoir
(3) Gas outlet
(5) Electric furnace
(4) Reactor
(6) v.s. motor
(7) Cylinder
(8) Gas inlet

Fig. 1. Experimental apparatus for countercurrent reduction in a drum-type rotary fluidized bed.

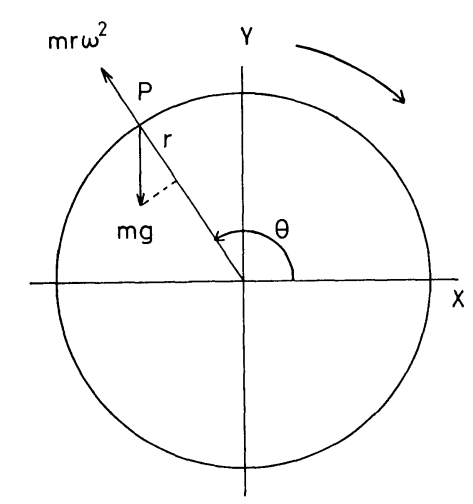

Fig. 2. Balance between centrifugal force and gravity.

For a reactor of $30 \mathrm{~cm}$ in diameter, $F$ is $77.2 \mathrm{rpm}$ and for the reduction reactor of $6.5 \mathrm{~cm}$ in diameter, it is $166 \mathrm{rpm}$.

Photograph 1 shows the fluidized state in different conditions of filling ratio and rotary speed. At the filling ratio of $10 \%$, the fluidized state could not be observed for any revolution. The conditions that the filling ratio was from 30 to $50 \%$ and the dimensionless rotary speed was from 1.0 to 1.2 , were suitable to the rotary fluidized state. At the filling ratio of $70 \%$, however, the fluidized region became a limited space.

2. Relation between Residence Weight of Powder Ore and Dimensionless Rotary Speed

As the apparent density of powder ore was $1.9 \mathrm{~g} /$ $\mathrm{cm}^{3}$, the powder ore, $315 \mathrm{~g}$ in weight, can be packed fully in this reaction zone, whose diameter is $6.5 \mathrm{~cm}$ and length is $5 \mathrm{~cm}$. The filling ratio is represented 


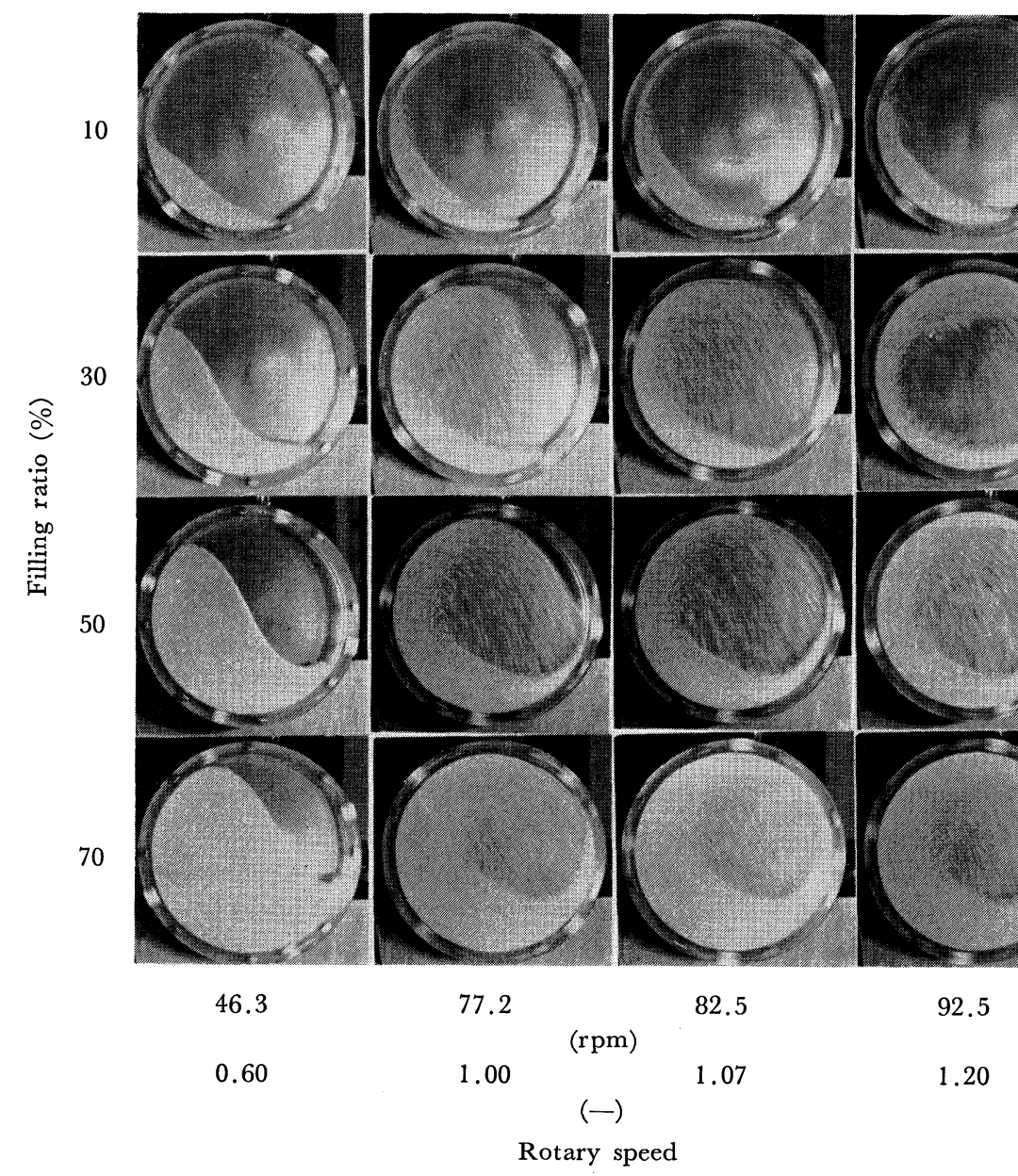

Photo. 1.

Motion of alumina particles $(D p=2 \mathrm{~mm})$ in a cold model of the drum-type rotary fluidized bed. by the reduced value of residence weight obtained by experiment. Figure 3 shows the relation between the filling ratio and the dimensionless rotary speed. In Fig. 3, a curve (a) shows the results without gas flow in reactor and the others were obtained by the reduction experiments.

Below the critical rotary speed, the filling ratio was nearly constant about $30 \%$. Over the critical speed, the filling ratio increased in proportion to the rotary speed, because the powder ore rotates with reactor. Therefore, the fluidized space becomes small.

\section{Characteristics of Mixing in Drum-type Rotary Fluid- ized Bed}

In order to investigate a mixing behavior of particles in the reactor inclined $1.1 \mathrm{deg}$, the internal age distribution function was obtained by using impulse response method as following procedure.

The magnesia particles were used for a charged material, and the magnetite (Kiruna) ore of the same size was used as a tracer. At the intervals of $2 \mathrm{~min}$, the magnesia particles in each weight $16 \mathrm{~g}$ were charged into the reactor. After being a constant discharge rate, the magnetite ore $20 \mathrm{~g}$ in weight was charged just once instead of magnesia particles. The discharged particles were gathered for $15 \mathrm{sec}$ at intervals of $1 \mathrm{~min}$. The gathered particles were separated magnetically into magnetite ore and magnesia particles.

On the assumption of perfect back-mixing flow, the tracer may be dispersed simultaneously in the vessel

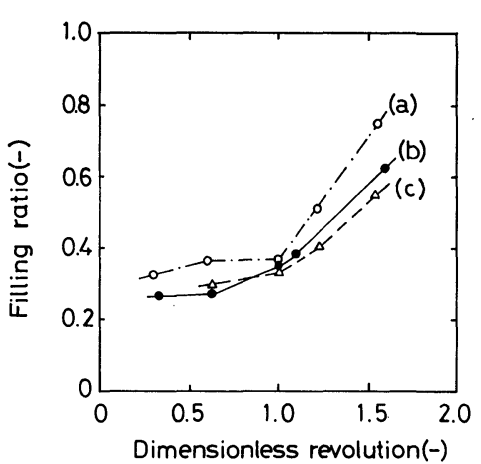

(a)

(b)

Temp.: Room temp. $900{ }^{\circ} \mathrm{C}$

Ore size $(\mathrm{mm}): \quad 0.42 \sim 0.71 \quad 0.71 \sim 1.00 \quad 0.42 \sim 0.71$ Charge rate $(\mathrm{g} / \mathrm{min}): \quad 20 \quad 6 \quad 10$

Fig. 3. Relation between filling ratio and dimensionless revolution.

where the concentration of tracer is uniform, the same as the exit concentration. Thus the following equation is given,

$$
\frac{d C}{d t}=-C / \tau
$$

By integrating Eq. (3) with instantaneous concentration $C_{0}$ at time zero, the following equation is obtained.

$$
C=C_{0} \exp (-t / \tau)
$$


However, the change of residual concentration of tracer in reactor with time shows as a form $C_{0}$ $\exp \left[\left(t-t_{b}\right) / \tau\right]$ as shown in Fig. 4, the linearlity was obtained at each revolution. Therefore, the behavior of powder ore in the drum-type rotary fluidized bed was seemed to be a back-mixing flow. Here $t_{b}$ may represent traveling time in the axis-tube connected with both sides of reactor. In the range of dimensionless rotary speed $(F)$ from 0.9 to $1.2, t_{b}$ was $2 \mathrm{~min}$, $t_{b}$ was $0.5 \mathrm{~min}$ at $F=1.6$, and $t_{b}$ was $5.3 \mathrm{~min}$ under $F=0.5$. These different data on $t_{b}$ were not enough to understand the major cause, but that may be probably affected by plug flow ${ }^{23)}$ and by-passing flow. ${ }^{24)}$

\section{Countercurrent Reduction in Drum-type Rotary Fluidized Bed}

\section{Effect of Rotary Speed on Gas Utilization}

At the constant conditions for countercurrent reduction in the rotary fluidized bed, such as charge rate of powder ore $W_{\mathrm{s}}$, gas flow rate $Q$, reduction temperature $900{ }^{\circ} \mathrm{C}$ and ore size $D p$, the experiments were done as a parameter of rotary speed. In the experiments at first $\mathrm{CO}$ gas only flowed into the reactor, and then the powder ore was charged. The steady state of reduction reaction and reduction degree were obtained from the measurement of waste-gas composition and discharge rate of reduced iron. Figure 5 shows the utilization coefficient, or $\mathrm{CO}_{2}$ concentration of exit gas depended on the dimensionless rotary speed. The maximum gas utilization coefficient was given at critical revolution, because the rotary fluidized state was sufficiently formed. Furthermore, sticking or sintering during reduction was not observed at any revolution but a growth of ring as like as thin film about $2 \mathrm{~mm}$ wide occurred on and off at the edge of reactor connected with branch-tube for gas-inlet.

\section{Rate Expression for Reduction of Ore Particles, and Dimensionless Numbers for Countercurrent Reduc- tion}

A mathematical model is considered for reduction in fixed bed and applied to countercurrent reduction as follows.

A rate expression was previously applied to the reduction of iron ore in a fixed bed ${ }^{25)}$ and in moving bed $^{26)}$ by the use of unreacted-core model based on the chemical reaction at three interfaces $\mathrm{Fe}_{2} \mathrm{O}_{3}-\mathrm{Fe}_{3} \mathrm{O}_{4}(\mathrm{~h})$, $\mathrm{Fe}_{3} \mathrm{O}_{4}-\mathrm{FeO}(\mathrm{m})$ and $\mathrm{FeO}-\mathrm{Fe}(\mathrm{w})$, and the diffusion through these layers. For example at $\mathrm{FeO}-\mathrm{Fe}(\mathrm{w})$ interface, the rate expression of wustite reduction is described as follows:

$$
\begin{aligned}
\frac{d R_{\mathrm{w}}}{d t}= & \frac{3 K_{\mathrm{w}}\left(C_{\mathrm{w}}^{\mathrm{eq}}-C_{\mathrm{w}}\right)}{r_{\mathrm{o}} \rho_{\mathrm{o}}} \\
& \times \frac{1}{\left(1-R_{\mathrm{w}} / R_{\mathrm{w}}^{\circ}\right)^{-2 / 3}+F_{\mathrm{w}}\left\{\left(1-R_{\mathrm{w}} / R_{\mathrm{w}}^{\circ}\right)^{-1 / 3}-1\right\}}
\end{aligned}
$$

where, $F_{\mathrm{w}}=K_{\mathrm{w}} r_{\mathrm{o}} / D_{\mathrm{w}}$

For the other rate expressions of hematite and magnetite reduction, the same equations can be described instead of suffix $w$ to $h$ and $m$.

The reduction reaction proceeds independently at three interfaces and its calculation was done in reduc-
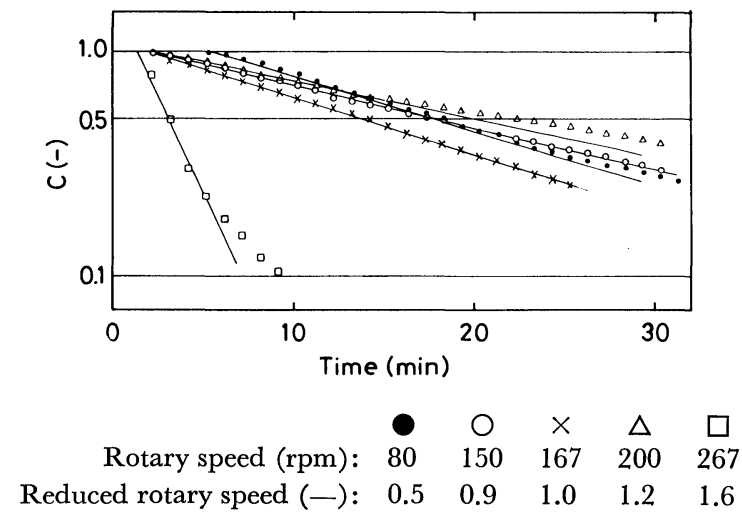

Fig. 4. Relation between residual fraction $C$ of tracer in reactor and time.

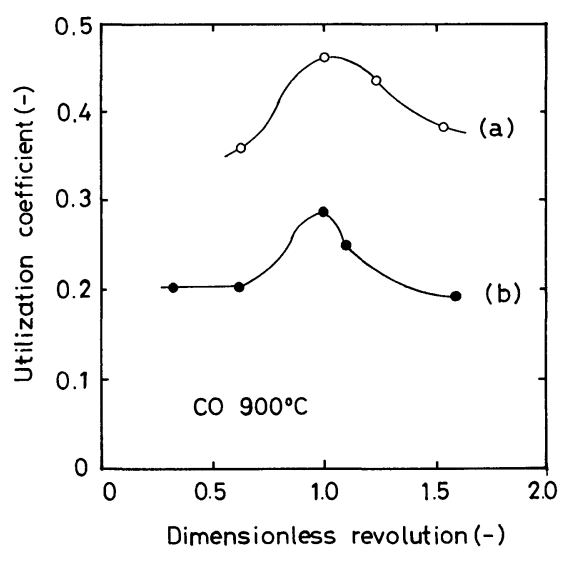

(a)

(b)

$\begin{array}{rcc}\text { Ore size }(\mathrm{mm}): & 0.42 \sim 0.71 & 0.71 \sim 1.00 \\ \text { Charge rate }(\mathrm{g} / \mathrm{min}): & 10.2 & 6.2 \\ \text { CO flow rate }(\mathrm{N} l / \mathrm{min}): & 2.1 & 3.2\end{array}$

Fig. 5. Dependency of utilization coefficient at the steady state on dimensionless revolution.

tion sequence of hematite, magnetite and wustite. The reduction degree $\mathrm{R}_{j}$ of the $j$-th unit layer represents the sum of each reduction degree step;

$$
R_{j}=R_{\mathrm{h}}+R_{\mathrm{m}}+R_{\mathrm{w}}
$$

An increment of gas utilization coefficient $d C_{i}$ in each reduction step per ore weight $d W$ is given by the following equation.

$$
\frac{d C_{i}}{d W}=\frac{1400 \cdot X_{\mathrm{o}}}{Q \cdot X_{\mathrm{r}}} \cdot \frac{d R_{i}}{d t}
$$

The increment of gas utilization coefficient $d C_{i}$ for each reduction step in unit layer was added in reduction sequence of hematite, magnetite and wustite. The sum of $d C_{i}$ corresponds to the initial concentration in next upper layer.

A calculated curve that represented the relation between gas utilization coefficient and reduction degree was made to fit with the observed data in a fixed bed at the reduction degree of 10,30, 60 and $80 \%$. The rate constants, such as $K_{i}$ chemical reaction rate constant of reduction step $i$ and $F_{i}$ defined as $F_{i}=K_{i} r_{\mathrm{o}} / D_{i}$, were altered with iteration. The results were sum- 
merized in Table 2. The reduction reaction may be considered as chemical controlling reaction, because the contribution ratio $F_{i}$ of diffusion to chemical reaction is smaller than 0.5 as shown in Table 2 .

The gas utilization coefficient and the reduction degree for countercurrent reduction on steady state can be obtained by using dimensionless numbers of rate constants and experimental conditions as follows.

(1) Dimensionless Traveling-time of Ore: $O t$

The rate of interfacial reaction $v_{0}$ is represented as $K \cdot X_{\mathrm{r}} / \rho_{\mathrm{o}}(\mathrm{cm} / \mathrm{min})$. The required time for the perfect reduction is given by $r_{\mathrm{o}} / v_{0}$. When the traveling-time of ore is given by $t_{0}$, the dimensionless traveling-time of ore is described by the following equation.

$$
O t=\frac{t_{\mathrm{o}}}{r_{\mathrm{o}} / v_{\mathrm{o}}}=\frac{\kappa \cdot X_{\mathrm{r}} \cdot t_{\mathrm{o}}}{r_{\mathrm{o}} \rho_{\mathrm{o}}}
$$

In general, the traveling-time of ore in a reaction zone can be described as

$$
t_{\mathrm{o}}=M / W_{\mathrm{s}}(\min )
$$

where, $M:$ the holding weight of ore in a reactor

$W_{\mathrm{s}}$ : the charging rate of ore.

In the drum-type rotary fluidized bed, however the holding weight, or residence weight of powder ore could not be consistent with reacting weight of ore in the reaction zone as discussed later.

(2) Dimensionless Contact-time of gas: $G c$

The gas volume generated at the incipient reduction per surface of ore is given as

$$
\frac{22400}{16} \cdot \kappa \cdot X_{\mathrm{r}} \cdot X_{\mathrm{o}}=1400 \cdot \kappa \cdot X_{\mathrm{r}} \cdot X_{\mathrm{o}}\left(\mathrm{cm}^{3} / \mathrm{cm}^{2} \mathrm{~min}\right)
$$

Total surface of ore in unit layer $\mathrm{A}$ is represented as $3 W / r_{0} \rho_{o}\left(\mathrm{~cm}^{2}\right)$. Thus the reducing volume per surface area of ore in unit layer is given by $Q \cdot X_{\mathrm{r}} / A$. Therefore, the ratio of the generated gas volume at the incipient reduction to the reducing gas volume represents a dimensionless gas volume, and hence its reciprocal value represents the dimensionless contacttime of gas $G c$;

$$
G c=\frac{1400 \cdot K \cdot X_{\mathrm{r}} \cdot X_{\mathrm{o}}}{Q r \cdot X_{\mathrm{r}} / A}=\frac{1400 \cdot K \cdot X_{\mathrm{o}} \cdot A}{Q}
$$

The ratio $\mathrm{Gc} / \mathrm{Ot}$ corresponds to three times of oxygen balance $B_{0}$.

Table 2. Rate constants $K_{i}, F_{i}$ and equilibrium con-

\begin{tabular}{|c|c|c|c|c|c|c|}
\hline \multirow{2}{*}{ 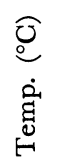 } & \multicolumn{3}{|c|}{ Rate constants } & \multicolumn{3}{|c|}{ Equilibrium conc. } \\
\hline & $\kappa_{\mathrm{w}}$ & $\left(\begin{array}{c}K_{\mathrm{m}} \\
\left(=K_{\mathrm{h}}\right)\end{array}\right.$ & $\begin{array}{l}F_{\mathrm{w}} \\
\left(=F_{\mathrm{m}}\right. \\
\left.=F_{\mathrm{h}}\right)\end{array}$ & $C_{\mathrm{w}}$ & $C_{\mathrm{m}}$ & $C_{\mathrm{h}}$ \\
\hline 900 & 0.030 & 0.012 & 0.15 & 0.318 & 0.787 & 1.0 \\
\hline 750 & 0.015 & 0.005 & 0.15 & 0.377 & 0.673 & 1.0 \\
\hline
\end{tabular}
centration $C_{i}$ for countercurrent reduction in a drum-type rotary fluidized bed (CO gas).

$$
\frac{G c}{O t}=\frac{3\left(W \cdot X_{\mathrm{o}} / t_{\mathrm{o}}\right)}{\left(Q \cdot X_{\mathrm{r}} / 1400\right)}=3 B_{\mathrm{o}}
$$

3. Gas Utilization Diagram for Countercurrent Reduction in Drum-type Rotary Fluidized Bed

On steady state of countercurrent reduction, the reduced oxygen of ore balances with that of reducing gas;

$$
Q \cdot U_{\mathrm{s}} \cdot \frac{16}{22400}=W_{\mathrm{s}} \cdot X_{\mathrm{o}} \cdot R_{\mathrm{s}}
$$

Thus the reduction degree on steady state was obtained by the observed data of gas utilization coefficient as following equation.

$$
R_{\mathrm{s}}=\frac{Q \cdot U_{\mathrm{s}} \cdot X_{\mathrm{r}}}{1400 \cdot W_{\mathrm{s}} \cdot X_{\mathrm{o}}}=\frac{1}{B_{\mathrm{o}}} \cdot U_{\mathrm{s}}
$$

The gas utilization coefficient, or $\mathrm{CO}_{2}$ concentration of exit gas did not exceed a stoichiometric concentration in each reduction step. Furthermore the movement of powder ore in the drum-type rotary fluidized bed as observed was almost back-mixing flow state. Therefore this reactor can be considered as a singlestage fluidized bed (number of unit layer $j$ is one in Eq. (6)) for a mathematical calculation using the rate constants as shown in Table 2.

Figures 6 and 7 show the relation between the gas utilization coefficient and the reduction degree at the temperature 900 and $750{ }^{\circ} \mathrm{C}$. These data are summarized in Table 3. In the figures, solid curves and dotted curves indicate the contour for the dimensionless contact-time of gas $G c$ and dimensionless traveling-time of ore $O t$, respectively. A straight line corresponds to three times each oxygen balance $3 B_{0}$.

For the calculation on $G c$ and $O t$, the actual residence-time of ore, or the ore weight $M$ as shown in Eq. (9) must be made a rough estimation, because $M$ means the actual weight of ore stayed in this reactor, but it does not represent the weight of ore reacted with reducing gas. We assumed that the reacting ore weight corresponded to $14.8 \%$ of the holding ore. This is a ratio of crosssectional area between branchtube and drum part (reaction zone) described as $2.5^{2} /$ $6.5^{2}=0.148$. According to the experimental results, the average weight of stayed ore as ferric oxide in the reaction zone was obtained about $150 \mathrm{~g}$. Hence, we supposed for the mathematical calculation that the ore weight $22.2 \mathrm{~g}$ reacted uniformly with reducing gas in the reaction zone. The value 0.148 may be considered that the over-all rate of reduction in this fluidized reactor is as small as 0.148 times of that in the fixed bed.

The calculated results as mentioned above were in good agreement with observed data. However, with respective results of reduction, there is a little difference from observed data. This may be depended on the both effects of by-passing flow and plug flow. And also this cause should be discussed on reduction distribution of powder ore based on internal age distribution function in the various reactors of the drumtype rotary fluidized bed. ${ }^{27)}$ 


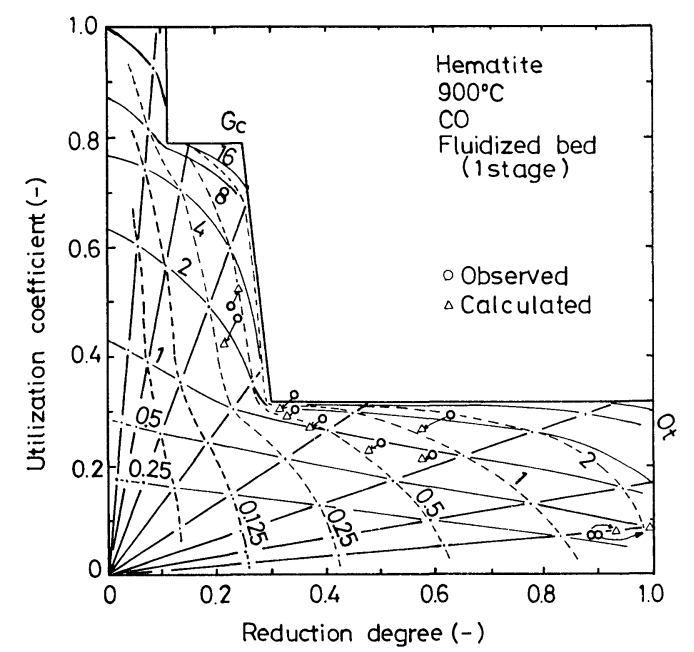

Fig. 6. Utilization diagram for countercurrent reduction in a drum-type rotary fluidized bed.

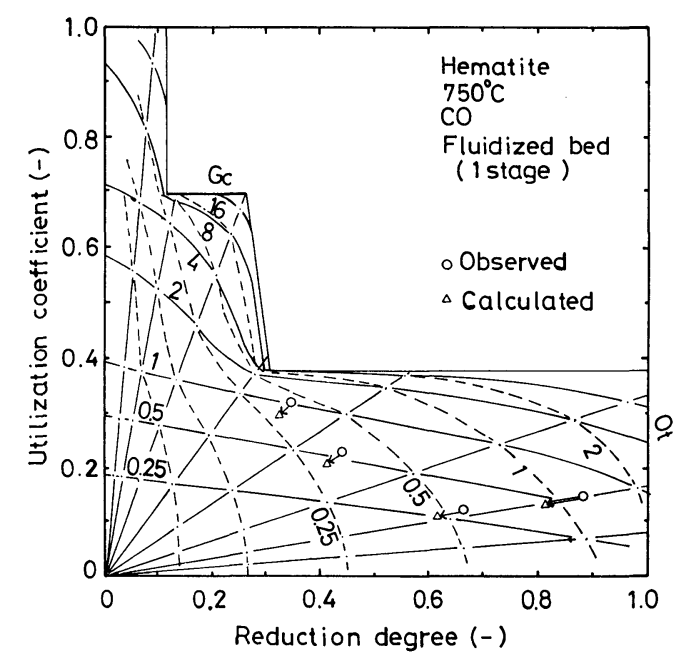

Fig. 7. Utilization diagram for countercurrent reduction in a drum-type rotary fluidized bed.

\section{Conclusion}

In the drum-type rotary fluidized bed reactor which has a single-room for reaction zone (inner diameter of $65 \mathrm{~mm}$ ) and two branch-tubes (inner diameter of $25 \mathrm{~mm}$ ) for charge and discharge of powder ore rotated at critical revolution $166 \mathrm{rpm}$ and with a slight gradient ( 1 and $3 \mathrm{deg}$ ), the experiments on countercurrent reduction with $\mathrm{CO}$ gas and on motion of particles were carried out and then the following results were obtained.

(1) On the conditions that the filling ratio was from 30 to $50 \%$ and the dimensionless rotary speed was from 1.0 to 1.2 , the rotary fluidized state and the stable quantity of stayed ore were obtained and the motion of powder ore was almost back-mixing flow.

(2) The maximum gas utilization coefficient, or $\mathrm{CO}_{2}$ concentration of waste gas, on steady state was obtained at the critical revolution.

(3) The reduction reaction of powder ore in this reactor was dealt with a reaction in a single fluidized bed characterized by back-mixing flow.

(4) The sintering phenomena in this reactor was merely observed. The gas-utilization coefficient could not be increased up to the stoichiometric equilibrium concentration in each reduction step. For a mathematical calculation based on three-interface unreacted core model, two dimensionless numbers, $G c$ and $O t$, applied to the countercurrent reduction were obtained by assuming the uniform reduction degree of powder ore and the quantity of actual reacting ore $14.8 \%$ of stayed ore in this reactor. The calculated results were in good agreement with observed data at the temperature of 750 and $900{ }^{\circ} \mathrm{C}$.

\section{Nomenclature}

$A: \quad$ total surface of powder ore $\left(\mathrm{cm}^{2}\right)$

$B_{0}$ : oxygen balance $(-)$

$C_{0}, C:$ tracer concentration at time zero and time $\mathrm{t}$ $(-)$

Table 3. Results of experimental data.

\begin{tabular}{|c|c|c|c|c|c|c|c|c|c|c|}
\hline $\begin{array}{l}\text { Exp. } \\
\text { No. }\end{array}$ & $\begin{array}{c}W_{\mathrm{s}} \\
(\mathrm{g} / \mathrm{min})\end{array}$ & $\underset{(\mathrm{N} l / \mathrm{min})}{Q}$ & $\begin{array}{l}M \\
(\mathrm{~g})\end{array}$ & $\stackrel{U_{\mathrm{s}}}{(-)}$ & $\stackrel{R_{\mathrm{S}}}{(-)}$ & $\begin{array}{c}G c \\
(-)\end{array}$ & $\stackrel{O t}{(-)}$ & $\stackrel{B_{\mathrm{o}}}{(-)}$ & $\begin{array}{l}\text { Temp. } \\
\left({ }^{\circ} \mathrm{C}\right)\end{array}$ & $\begin{array}{c}\theta \\
(\mathrm{deg})\end{array}$ \\
\hline 1 & 11.4 & 2.13 & 126.7 & 0.472 & 0.235 & 1.73 & 0.288 & 2.00 & \multirow{11}{*}{900} & \multirow{7}{*}{2.9} \\
\hline 2 & 5.53 & 2.14 & 105.2 & 0.309 & 0.319 & 1.43 & 0.492 & 0.968 & & \\
\hline 3 & 5.93 & 1.01 & 114.6 & 0.491 & 0.223 & 3.31 & 0.500 & 2.21 & & \\
\hline 4 & 2.77 & 1.07 & 101.0 & 0.331 & 0.341 & 2.75 & 0.944 & 0.971 & & \\
\hline 5 & 5.51 & 4.29 & 110.9 & 0.240 & 0.498 & 0.753 & 0.510 & 0.492 & & \\
\hline 6 & 2.64 & 2.16 & 109.3 & 0.289 & 0.630 & 1.47 & 1.07 & 0.458 & & \\
\hline 7 & 6.41 & 3.28 & 115.5 & 0.288 & 0.393 & 1.03 & 0.466 & 0.737 & & \\
\hline $8^{*}$ & 5.48 & 2.36 & 212.4 & 0.305 & 0.349 & 2.62 & 1.00 & 0.873 & & \multirow{4}{*}{1.1} \\
\hline 9 & 1.01 & 4.58 & 127.6 & 0.075 & 0.908 & 0.812 & 3.27 & 0.083 & & \\
\hline $10 * *$ & 2.48 & 2.23 & 67.4 & 0.225 & 0.601 & 0.881 & 0.704 & 0.417 & & \\
\hline $11 * *$ & 1.00 & 4.44 & 67.4 & 0.075 & 0.893 & 0.442 & 1.74 & 0.085 & & \\
\hline 12 & 5.29 & 2.09 & 137.4 & 0.321 & 0.355 & 0.768 & 0.269 & 0.952 & \multirow{4}{*}{750} & \multirow{4}{*}{1.1} \\
\hline 13 & 5.56 & 3.96 & 145.3 & 0.229 & 0.436 & 0.428 & 0.271 & 0.526 & & \\
\hline 14 & 2.88 & 6.00 & 128.4 & 0.120 & 0.665 & 0.245 & 0.460 & 0.178 & & \\
\hline 15 & 1.33 & 3.07 & 106.5 & 0.143 & 0.882 & 0.404 & 0.828 & 0.163 & & \\
\hline
\end{tabular}

*: Reactor length is $100 \mathrm{~mm}$; **: Reactor length is $25 \mathrm{~mm}$; the other's length is $50 \mathrm{~mm}$. 
$C_{i}^{\text {eq }}$ : equilibrium $\mathrm{CO}_{2}$ concentration in reduction step $i(-)$

$C_{i}: \quad \mathrm{CO}_{2}$ concentration of gas in reduction step $i$ $(-)$

$C_{j}: \quad \mathrm{CO}_{2}$ concentration of gas in unit layer $j(-)$

$D_{i}$ : gas diffusion coefficient in reduction step $i$ $(\mathrm{g} / \mathrm{cm} \cdot \mathrm{min})$

$D p:$ mean size of iron ore $(\mathrm{cm})$

$D_{t}$ : diameter of drum-type reactor $(\mathrm{cm})$

$F_{i}$ : contribution ratio of diffusion to chemical reaction in reduction step $i(-)$

$F, f: \quad$ critical rotary speed (rpm, rps)

$g:$ acceleration of gravity $\left(980 \mathrm{~cm} / \mathrm{s}^{2}\right)$

Gc: dimensionless contact-time of gas (-)

$K$ : chemical reaction-rate constant $\left(\mathrm{g} / \mathrm{cm}^{2} \cdot \mathrm{min}\right)$

$K_{i}$ : chemical reaction-rate constant in reduction step $i\left(\mathrm{~g} / \mathrm{cm}^{2} \cdot \min \right)$

$M:$ residence weight of ore in reactor $(\mathrm{g})$

$m:$ mass of iron ore (g)

$O t$ : dimensionless travelling-time of ore (-)

$Q:$ gas flow-rate $\left(\mathrm{cm}^{3} / \mathrm{min}\right)$

$r$ : radius of rotary fluidized bed reactor $(\mathrm{cm})$

$r_{0}:$ radius of powder ore $(\mathrm{cm})$

$R_{i}$ : reduction degree in reduction step $i(-)$

$R_{i}^{\circ}$ : final reduction degree in reduction step $i(-)$

$R_{j}$ : reduction degree of unit layer $j(-)$

$R_{\mathrm{s}}$ : reduction degree of countercurrent reduction at steady state (-)

$t: \quad$ time (min)

$t_{b}:$ traveling-time in branch tube ( $\mathrm{min}$ )

$t_{0}:$ traveling-time of ore (min)

$U_{\mathrm{s}}$ : gas utilization coefficient of countercurrent reduction at steady state $(-)$

$v_{0}$ : rate of interfacial reaction $(\mathrm{cm} / \mathrm{min})$

$W:$ weight of ore reacted continuously with reducing gas in reactor $(\mathrm{g})$

$W_{\mathrm{s}}$ : charge rate of ore $(\mathrm{g} / \mathrm{min})$

$X_{\mathrm{o}}$ : combined oxygen concentration of ore (-)

$X_{\mathrm{r}}$ : $\mathrm{CO}$ concentration of reducing gas $(-)$

$\rho_{0}:$ density of ore $\left(4.0 \mathrm{~g} / \mathrm{cm}^{3}\right)$

$\omega:$ angular velocity $(\mathrm{rad} / \mathrm{s})$

$\tau:$ mean residence time of tracer $(\min )$

Suffix

$i(\equiv \mathrm{h}, \mathrm{m}, \mathrm{w})$ : reduction step of hematite, magnetite and wustite

\section{REFERENCES}

1) N. Nishida: Tetsu-to-Hagané, 62 (1976), 705.

2) K. Kondo and Y. Matsushita: Tetsu-to-Hagané, 46 (1960), 64.

3) J. Astier: Rev. Mét., 72 (1975), 711.

4) K. Olrich: Stahl und Eisen, 98 (1978), 1211.

5) S. Kondo: Tetsu-to-Hagané, 60 (1974), 1542.

6) I. Ichijima, S. Kondo, R. Matsumoto, M. Sugata and T. Nakazawa: Tetsu-to-Hagané, 51 (1965), 647.

7) I. Ichijima, S. Kondo, R. Matsumoto, M. Sugata and H. Ishikawa: Tetsu-to-Hagané, 51 (1965), 649.

8) Y. Yamamich: Tetsu-to-Hagané Overseas, 3 (1963), 296.

9) K. Kamiya, K. Sakuraya, I. Morinaka, N. Kitahara, M. Ozawa and M. Tanaka: Tetsu-to-Hagané, 65 (1979), 169.

10) K. Sakuraya, N. Kitahara, I. Morinaka, K. Kamiya, M. Ozawa and M. Tanaka: Tetsu-to-Hagané, 65 (1979), 176.

11) I. Morinaka, K. Kamiya, K. Sakuraya, N. Kitahara, M Ozawa and M. Tanaka: Tetsu-to-Hagané, 65 (1979), 185.

12) A. Okura, M. Tokuda and Y. Matsushita: Tetsu-to-Hagané, 48 (1962), 1039.

13) K. Sakuraya, K. Kamiya and M. Tanaka: Tetsu-to-Hagané, 63 (1977), 1435.

14) H. Schenck, W. Wenzel and H. D. Butzmann: Arch. Eisenhüttenw., 33 (1962), 211.

15) W. Wenzel, F. R. Block and E. Wortberk: Arch. Eisenhüttenw., 43 (1972), 805.

16) S. Y. Ezz: Trans. Met. Soc. AIME, 218 (1960), 709.

17) T. Hamada and T. Shirai: Kagaku Kogaku (Chem. Eng. Japan), 29 (1965), 995.

18) N. Inoue, Y. Nakano, M. Ishida and T. Shirai: Kagaku Kogaku Ronbunshu (Chem. Eng. Japan), 4 (1978), 135.

19) T. Sōma: Tetsu-to-Hagané, 52 (1966), 1320.

20) T. Sōma: Trans. ISIJ, 11 (1970), 480.

21) T. Sōma: Tetsu-to-Hagané, 58 (1972), 1557.

22) Y. Sasaki and T. Sōma: Tetsu-to-Hagané, 60 (1974), S342.

23) S. Nagata, W. Eguchi, T. Imamura, K. Tanigawa and T. Tanaka: Kagaku Kogaku (Chem. Eng. Japan), 10 (1953), 387.

24) D. H. Himmelblau and K. B. Bischoff: Process Analysis and Simulation, John Wiley \& Sons Inco., New York, (1968).

25) T. Sōma: Tetsu-to-Hagané, 61 (1975), 909.

26) M. Amatatsu and T. Sōma: Tetsu-to-Hagané, 62 (1976), S383.

27) K. Kobayashi, M. Amatatsu and T. Sōma: Tetsu-toHagané, 68 (1982), S777. 